\title{
PENGEMBANGAN PTERIDISC POKOK BAHASAN PTERIDOPHYTA SEBAGAI MEDIA PEMBELAJARAN TAKSONOMI TUMBUHAN
}

\author{
Anna Nurlia $^{1)}$, Bambang Hariyadi ${ }^{2)}$, Muswita, ${ }^{2)}$ \\ Program Studi Pendidikan BIologi Universitas Jambi \\ e-mail: AnnaNurlia11@yahoo.com
}

\begin{abstract}
.
Standards learning competency plant taxonomy is, students can understand and explain the principles of classification, description, identification, nomenclature, and knowing the morphological and anatomical structure of plants. Students can achieve competence learning if the student successfully mastered the material plant taxonomy. The absence of appropriate learning media to optimize students' understanding of the taxonomy of plant material can cause difficulties or obstacles for students to understand the material plant taxonomy. Therefore, the development of instructional media in the form of Pteridisc needs to be done. The purpose of this study was to determine the end product of learning media Pteridisc on the subject of Pteridophyta and to determine the response students of Biology Education PMIPA FKIP University of jambi to use as a learning medium Pteridisc plant taxonomy. Based on the results obtained validation, assessment for each indicator on the design aspects of the media were on both criteria with the average percentage of $75 \%$, and ratings for the indicators on the material aspects of the media are on the criterion of good and very good, with a mean percentage of 86 , $7 \%$. Student responses to assessment of each indicator in the trial against the use of a small group of media currently on the criteria very well with the average of the responses given percentage $94.23 \%$, and student responses to assessment of each indicator in a large group trials are in very good criteria with the average percentage of $87.82 \%$. It can be concluded that the instructional media products Pteridisc subject Pteridophyta included in the criteria very well, so it can be used by the student in learning activities.
\end{abstract}

Keywords: development, instructional media, taxonomy Pteridophyta

\section{PENDAHULUAN}

Standar kompetensi pembelajaran

mata kuliah taksonomi tumbuhan yaitu, mahasiswa dituntut mampu memahami dan menjelaskan prinsip pengklasifikasian, pen deskripsian, pengidentifikasian, tatanama, tinjauan taksa pada tumbuhan serta mengetahui karakter struktur morfologi dari tumbuhan. Untuk dapat memaksimalkan penguasaan mahasis- wa terhadap materi pada mata kuliah taksonomi tumbuhan, maka dalam pelaksan- aan kegiatan perkuliahan diperlukan media yang efektif dan menarik, agar mahasiswa dapat lebih cepat memahami taksa tumbuhan yang ditentukan berdasarkan kesamaan maupun perbedaan karakter morfologi serta anatomi.

Dalam kegiatan perkuliahan, penggunaan media pembelajaran memiliki peranan yang penting dalam membantu 
pemahaman mahasiswa terhadap bagianbagian materi mata kuliah taksonomi tumbuhan yang sulit dikuasai. Berdasarkan hasil observasi awal yang dilakukan di Program Studi Pendidikan Biologi FKIP Universitas Jambi, didapatkan bahwa mahasiswa menyatakan merasa kesulitan dalam menguasai materi dalam mata kuliah taksonomi tumbuhan, salah satunya materi mengenai klasifikasi serta belum tersedianya media yang menarik dan cukup efektif untuk memudahkan dalam memahami materi klasifikasi tumbuhan pada mata kuliah taksonomi tumbuhan.

Untuk memenuhi kebutuhan akan media pembelajaran yang menarik dan dapat memudahkan mahasiswa dalam memahami materi pokok bahasan klasifikasi divisi tumbuhan paku, maka pengembangan media pembelajaran yang kreatif dan menarik dalam bentuk Pteridisc perlu dilakukan. Pteridisc merupakan media pembelajaran yang pengembangannya dilatarbelakangi berdasarkan media pembelajaran Magic disc. Magic disc sendiri merupakan media pembelajaran yang belum banyak dikenal dalam kalangan masyarakat. Anonim (2011:1) berpendapat bahwa Magic disc terdiri dari dua bagian berbentuk lingkaran (Disc). Antara satu bagian dengan bagian yang lain disatukan dengan kancing (as) pada bagian tengah. Cara kerjanya diputar salah satu bagian atau kedua-duanya searah jarum jam atau sebaliknya. Sehingga bernilai praktis dan sangat membantu dalam proses belajar mengajar.

Dari hasil studi terdahulu mengenai Magic disc, diketahui bahwa masih sedikit pengembangan Magic disc untuk pembelajaran biologi. Magic disc banyak digunakan dalam pembelajaran yang menggunakan rumus seperti matematika, kimia, fisika, serta bahasa inggris. Harmini (2009:1) meyebutkan bahwa, Magic disc merupakan media pembelajaran yang memiliki fungsi semantik khususnya dalam pelafalan atau pemahaman simbol-simbol, nama-nama atau istilah asing, rata - rata hasil pelajaran bahasa inggris meningkat setelah diberi perlakuan dengan menggunakan permainan bingo maupun Magic disc secara berulang-ulang.

Magic disc juga sudah banyak dimodifikasi dalam berbagai bentuk. Penelitiannya Kusrini (2009:1) menyebutkan bahwa penggunaan media audiovisual Magic english dapat meningkatkan memotivasi siswa secara signifikan dalam mempelajari bahasa. Dengan demikian dapat dinyatakan bahwa pengembangan Pteridisc pada materi pokok bahasan Pteridophyta, cukup ideal dilakukan dalam membantu 
penguasaan atau pemahaman mahasiswa terhadap materi klasifikasi Pteridophyta. Hasil penelitian Ananda et al (2014:1) menguatkan dasar dilakukannya pengemban- gan Pteridisc, bahwa Angdisc yang dikem- bangkan untuk mata kuliah taksonomi tumbuhan Angiospermae sangat baik dalam membantu mahasiswa memahami materi pembelajaran taksonomi tumbuhan.

Pteridisc yang dikembangkan diharapkan dapat membantu mahasiswa dalam memahami dan menguasai materi yang diberikan secara berkelompok selama waktu perkuliahan di kelas maupun di luar kelas, dikarenakan Pteridisc yang dikembangkan memiliki keunggulan diantaranya, mampu menyajikan materi secara praktis mencakup class, ordo, dan familia dalam divisi Pteridophyta dengan penggunaan istilah yang mudah dimengerti, desain tulisan, gambar dan permainan yang menarik. Pteridisc yang dikembangkan ditujukan sebagai penunjang bagi mahasiswa untuk memudahkan mereka dalam mengelompokkan tumbuhan yang tergolong kedalam divisi Pteridophyta. Oleh karena itu, pengembangan Pteridisc pada materi pokok bahasan Pteridophyta perlu dilakukan. Berdasarkan uraian permasalahan tersebut, maka penulis melakukan penelitian mengenai "Pengembangan Pteridisc

\section{Pokok Bahasan Pteridophyta Sebagai Media Pembelajaran Tak- sonomi Tumbuhan"}

\section{METODE PENELITIAN}

Model pengembangan yang diterapkan dalam pengembangan Peteridisc adalah model ADDIE. ADDIE merupakan singkatan dari Analysis, Design, Development or Production, Implementation or Delivery and Evaluations. Model ini dapat digunakan untuk berbagai macam bentuk pengembangan produk seperti model, strategi pembelajaran, metode pembelajaran, media dan bahan ajar (Mulyatiningsih, 2009:5). Menurut Richey et al (2011:19) Model ini sesuai namanya terdiri dari lima fase atau tahap utama, yaitu (A)nalysis, (D)esain, (D)evelopment, (I)mplementation, dan (E)valuation.

Prosedur dalam pengembangan media pembelajaran Pteridisc merujuk pada model pengembangan ADDIE, yang terdiri dari lima tahapan yaitu analisis, desain, pengembangan, implementasi, dan evaluasi.

Terdiri atas tiga tahapan desain ujicoba yaitu, tahap I adalah tahap validasi oleh validator yang merupakan para ahli desain dan materi pembelajaran kemudian dilanjutkan dengan proses analisis data hasil validasi dan revisi. Selanjutnya pada tahap II 
dilakukan ujicoba kelompok kecil pada 5 mahasiswa dan dilanjutkan ke tahap III, dimana dilakukan ujicoba kelompok besar pada 15 mahasiswa sebagai subyek sasaran produk, pada setiap ujicoba data yang didapatkan dianalisis dan dilakukan revisi produk.

Subjek ujicoba penelitian terdiri dari mahasiswa Program Studi Pendidikan Biologi PMIPA FKIP Universitas Jambi, semester VI yang telah mengontrak mata kuliah taksonomi tumbuhan tahun angkatan 2012/2013, dimana untuk subjek ujicoba kelompok kecil sebanyak 5 orang mahasiswa dan untuk ujicoba kelompok besar sebanyak 15 orang mahasiswa.

Jenis data yang diambil yaitu data kuantitatif dan kualitatif. Data kualitatif berupa saran dan pernyataan kesesuaian media pembelajaran Pteridisc berdasarkan saran dan masukan dari validator, hasil data yang didapatkan digunakan sebagai acuan dalam revisi produk. Data kuantitatif meliputi hasil penilaian dari validator dan mahasiswa pada angket validasi media pembelajaran Pteridisc dan isian angket tanggapan mahasiswa terhadap penggunaan media pembelajaran Pteridisc.

Instrumen pengumpulan data yang digunakan dalam penelitian ini adalah angket. Riduwan (2013:26) menyatakan bentuk angket yang dibuat sebagai instrumen sangat beragam, antara lain angket terbuka dan tertutup. Angket terbuka ialah angket yang disajikan dalam bentuk sederhana sehingga responden dapat memberikan isian sesuai dengan kehendak dan keadaannya. Sedangkan, angket tertutup merupakan angket yang disajikan dalam bentuk sedemikian rupa sehingga responden diminta untuk memilih salah satu jawaban yang sesuai dengan pilihannya. Dalam penelitian ini, angket yang digunakan oleh validator merupakan gabungan angket terbuka dan tertutup.

Teknik analisis data dalam penilitian ini menggunakan teknik analisis data kualitatif dan kuantitatif. Perhitungan data kuantitatif yang diperoleh dihitung dengan melakukan uji skala pengukuran. Analisis data kualitatif dilakukan dengan mengumpulkan data berdasarkan saran dan komentar dari validator. Selanjutnya hasil data yang diperoleh dalam bentuk tekstural dianalisis dan dijadikan sebagai pertimbangan dalam melakukan revisi produk. 


\section{HASIL PENGEMBANGAN DAN PEMBAHASAN}

Media pembelajaran Pteridisc yang telah dikembagkan divalidasi oleh validator desain media dan validator materi, setelah media dinyatakan layak oleh validator desain media dan materi, media yang dikembangkan kemudian diujicobakan pada kelompok kecil, dan dilanjutkan pada ujicoba kelompok besar. Adapun hasil dan pembahasan dari data yang didapatkan adalah sebagai berikut:

\section{Validasi desain media}

\begin{tabular}{|c|c|c|c|c|}
\hline Indikator & $\begin{array}{c}\text { Jumlah } \\
\text { item }\end{array}$ & Skor & Kriteria & $\begin{array}{c}\text { Jumlah } \\
\text { skor }\end{array}$ \\
\hline \multirow{3}{*}{$\begin{array}{c}\text { Tampilan } \\
\text { media }\end{array}$} & 9 & 3 & Baik & 27 \\
\hline & \multicolumn{3}{|c|}{ Jumlah $\sum$} & 27 \\
\hline & \multicolumn{3}{|c|}{ Persentase $\%$} & $75 \%$ \\
\hline \multirow{3}{*}{$\begin{array}{l}\text { Fungsi } \\
\text { Media }\end{array}$} & 4 & 3 & Baik & 12 \\
\hline & \multicolumn{3}{|c|}{ Jumlah $\sum$} & 12 \\
\hline & \multicolumn{3}{|c|}{ Persentase $\%$} & $75 \%$ \\
\hline \multirow{3}{*}{$\begin{array}{c}\text {.Manfaat } \\
\text { media }\end{array}$} & 4 & 3 & Baik & 12 \\
\hline & \multicolumn{3}{|c|}{ Jumlah $\sum$} & 12 \\
\hline & \multicolumn{3}{|c|}{ Persentase $\%$} & $75 \%$ \\
\hline \begin{tabular}{|c|} 
Jumlah \\
keseluruhan
\end{tabular} & 17 & - & - & 51 \\
\hline Persentase & - & - & Baik & $75 \%$ \\
\hline
\end{tabular}

Berdasarkan hasil yang didapatkan pada validasi desain media, diketahui persentase kevalidan untuk aspek indikator tampilan, fungsi, dan manfaat media yaitu 75\%, angka ini berada pada rentang perentase $50 \%-75 \%$, berdasarkan perhitun- gan tersebut maka dapat dikatakan bahwa desain media yang dikembangkan sudah berada pada taraf baik. Dari hasil isian angket juga dapat diketahui bahwa masingmasing item penilaian pada aspek indikator sudah mendapatkan bobot penililaian baik atau sesuai. Setelah serang- kaian validasi media dilakukan, validator menyatakan media pembelajaran Pteridisc layak untuk diujicobakan pada kelompok kecil. Selain penilaian skor angket, dalam serangkaian validas media, pengembang juga banyak mendapatkan saran dan masukan dari validator untuk perbaikan desain media. Tujuannya adalah untuk mendapatkan kesempurnaan dari desain media yang dikembangkan, sebelum media siap untuk diujicobakan.

\section{Validasi materi}

\begin{tabular}{|c|c|c|c|c|}
\hline Indikator & $\begin{array}{c}\text { Jumlah } \\
\text { item }\end{array}$ & Skor & kriteria & $\begin{array}{c}\text { Jumlah } \\
\text { skor }\end{array}$ \\
\hline \multirow{4}{*}{ Kesesuaian } & 2 & 3 & Baik & 6 \\
\hline & 3 & 4 & $\begin{array}{c}\text { Sangat } \\
\text { Baik }\end{array}$ & 12 \\
\hline & \multicolumn{3}{|c|}{ Jumlah $\sum$} & 18 \\
\hline & \multicolumn{3}{|c|}{ Persentase $\%$} & $90 \%$ \\
\hline \multirow{3}{*}{ Ketepatan } & 2 & 3 & Baik & 6 \\
\hline & \multicolumn{3}{|c|}{ Jumlah $\sum$} & 6 \\
\hline & \multicolumn{3}{|c|}{ Persentase $\%$} & $75 \%$ \\
\hline \multirow{3}{*}{ Kemudahan } & 2 & 3 & Baik & 6 \\
\hline & \multicolumn{3}{|c|}{ Jumlah $\sum$} & 6 \\
\hline & \multicolumn{3}{|c|}{ Persentase $\%$} & $75 \%$ \\
\hline Kemenarikan & 2 & 3 & Baik & 6 \\
\hline
\end{tabular}




\begin{tabular}{|c|c|c|c|c|}
\hline & 4 & 4 & $\begin{array}{c}\text { Sangat } \\
\text { Baik }\end{array}$ & 8 \\
\hline & & $\mathrm{mla}$ & & 14 \\
\hline & & $\operatorname{sen}$ & & $91,6 \%$ \\
\hline & 1 & 3 & Baik & 3 \\
\hline Kelengkapan & 1 & 4 & $\begin{array}{c}\text { Sangat } \\
\text { Baik }\end{array}$ & 4 \\
\hline & & $\mathrm{mla}$ & & 7 \\
\hline & & $\operatorname{sen}$ & & $87,5 \%$ \\
\hline $\begin{array}{c}\text { Jumlah } \\
\text { keseluruhan }\end{array}$ & 17 & - & - & 59 \\
\hline Persentase & - & - & $\begin{array}{c}\text { Sangat } \\
\text { Baik }\end{array}$ & $86,7 \%$ \\
\hline
\end{tabular}

Analisis angket hasil ujicoba kelompok besar, dihitung berdasarkan lima aspek indikator yaitu, kesesuaian, ketepatan, kemudahan, kemenarikan dan kelengkapan media. Berdasarkan perhitungan angket validasi materi media pembelajaran Pteridisc maka didapatkan persentase skor penilaian yang meliputi lima aspek indikator yaitu, indikator kesesuaian materi 90\%, indikator ketepatan dan kemudahan materi $75 \%$, indikator kemenarikan materi 91,6\%, dan indikator kelengkapan materi $87,5 \%$. Dari perhitungan skor yang didapat untuk aspek indikator kesesuaian, kemenarikan, dan kelengkapan materi berada pada rentang persentase 75\%-100\%, maka dapat dinyatakan penilaian isi materi untuk aspek indikator kesesuaian, kemenarikan, dan kelengkapan berada pada taraf sangat baik. Untuk aspek indikator ketepatan dan kemudahan materi berada pada rentang persen- tase 50\%-75\%, dari hasil tersebut dapat dinyatakan bahwa penilaian materi untuk aspek indikator ketepatan dan kemudahan materi berada pada taraf baik. Dari hasil keseluruhan penilaian validator terhadap materi pada media pembelajaran Pteridisc maka validator menyatakan media layak untuk diujicobakan pada subjek ujicoba kelompok kecil.

Dalam validasi materi media pembelajaran Pteridisc, selain penilain skor isian angket, pengembang juga banyak mendapatkan saran atau masukan dari validator materi untuk perbaikan media yang dikembangkan, adapun perbaikan yang disarkan yaitu mengenai penggunaan istilah-istilah yang kurang tepat dan kesalah dalam pulisan. validator juga menyaran untuk memperhatikan penggunaan warna, gambar, dan media yang sebaiknya lebih diperbesar agar memudahkan mahasiswa dalam penggunaannya.

\section{Ujicoba kelompok kecil}

\begin{tabular}{|c|c|c|c|c|}
\hline \multirow{2}{*}{ Indikator } & $\begin{array}{c}\text { Jumlah } \\
\text { item }\end{array}$ & Skor & kriteria & $\begin{array}{c}\text { Jumlah } \\
\text { skor }\end{array}$ \\
\hline \multirow{3}{*}{ Tampilan } & 10 & 3 & Baik & 30 \\
\cline { 2 - 5 } & 15 & 4 & $\begin{array}{c}\text { Sangat } \\
\text { Baik }\end{array}$ & 60 \\
\cline { 2 - 5 } & \multicolumn{3}{|c|}{ Jumlah $\sum$} \\
\cline { 2 - 5 } Kemudahan & 2 & 3 & Baik & 60 \\
\cline { 2 - 5 } & 3 & 4 & Sangat & 12 \\
\hline
\end{tabular}




\begin{tabular}{|c|c|c|c|c|}
\hline & & & Baik & \\
\hline & \multicolumn{3}{|c|}{ Jumlah $\sum$} & 18 \\
\hline & \multicolumn{3}{|c|}{ Persentase $\%$} & $90 \%$ \\
\hline \multirow{4}{*}{ Kebermanfaatan } & 1 & 3 & Baik & 3 \\
\hline & 9 & 4 & $\begin{array}{c}\text { Sangat } \\
\text { Baik }\end{array}$ & 36 \\
\hline & \multicolumn{3}{|c|}{ Jumlah $\sum$} & 39 \\
\hline & \multicolumn{3}{|c|}{ Persentase $\%$} & $97,5 \%$ \\
\hline \multirow{4}{*}{ Kesesuaian } & 2 & 3 & Baik & 6 \\
\hline & 23 & 4 & $\begin{array}{c}\text { Sangat } \\
\text { Baik }\end{array}$ & 92 \\
\hline & \multicolumn{3}{|c|}{ Jumlah $\sum$} & 98 \\
\hline & \multicolumn{3}{|c|}{ Persentase $\%$} & $98 \%$ \\
\hline $\begin{array}{c}\text { Jumlah } \\
\text { keseluruhan }\end{array}$ & 65 & - & - & 243 \\
\hline Persentase & - & - & $\begin{array}{c}\text { Sangat } \\
\text { Baik }\end{array}$ & $94,23 \%$ \\
\hline
\end{tabular}

Ujicoba kelompok kecil dilakukan setelah media dinyatakan layak untuk dilakukan ujicoba oleh validator materi dan desain media. Berdasarkan hasil isian angket yang diperoleh selama ujicoba kelompok kecil dapat diketahui persentase penilaian skor untuk masing-masing aspek indikator yaitu, indikator tampilan media 90\%, indikator kemudahan media $90 \%$, indikator kebermanfaatan media $97,5 \%$, dan indikator kesesuai media 98\%. Perhitungan skor penilaian untuk tiap-tiap aspek indikator berada pada rentang persentase $75 \%-100 \%$, maka dapat dinyatakan produk media pembelajaran Pteridisc yang dikembangkan berada pada taraf sangat baik. Hasil penilain untuk ujicoba kelompok kecil juga tidak terlepas dari saran dan komentar dari subjek ujicoba (mahasiswa). Adapun saran yang diberikan antara lain, mengenai penulisan kata petu- njuk pada kartu deskripsi yang sebaiknya dibuat lebih spesifik dan ukuran tulisan pada media disarankan agar lebih diperbesar sehingga lebih mudah untuk dibaca dan dipahami.

\section{Ujicoba kelompok besar}

\begin{tabular}{|c|c|c|c|c|}
\hline Indikator & $\begin{array}{c}\text { Jumlah } \\
\text { item }\end{array}$ & Skor & Kriteria & $\begin{array}{c}\text { Jumlah } \\
\text { skor }\end{array}$ \\
\hline \multirow{4}{*}{ Tampilan } & 42 & 3 & Baik & 126 \\
\hline & 33 & 4 & $\begin{array}{c}\text { Sangat } \\
\text { Baik }\end{array}$ & 132 \\
\hline & \multicolumn{3}{|c|}{ Jumlah $\sum$} & 258 \\
\hline & \multicolumn{3}{|c|}{ Persentase $\%$} & $86 \%$ \\
\hline \multirow{4}{*}{ Kemudahan } & 10 & 3 & Baik & 30 \\
\hline & 5 & 4 & $\begin{array}{c}\text { Sangat } \\
\text { Baik }\end{array}$ & 20 \\
\hline & \multicolumn{3}{|c|}{ Jumlah $\sum$} & 50 \\
\hline & \multicolumn{3}{|c|}{ Persentase \% } & $91,6 \%$ \\
\hline \multirow{4}{*}{ Kebermanfaatan } & 15 & 3 & Baik & 45 \\
\hline & 15 & 4 & $\begin{array}{c}\text { Sangat } \\
\text { Baik }\end{array}$ & 60 \\
\hline & \multicolumn{3}{|c|}{ Jumlah $\sum$} & 105 \\
\hline & \multicolumn{3}{|c|}{ Persentase $\%$} & $87,5 \%$ \\
\hline \multirow{4}{*}{ Kesesuaian } & 33 & 3 & Baik & 99 \\
\hline & 42 & 4 & $\begin{array}{c}\text { Sangat } \\
\text { Baik }\end{array}$ & 168 \\
\hline & \multicolumn{3}{|c|}{ Jumlah $\sum$} & 267 \\
\hline & \multicolumn{3}{|c|}{ Persentase $\%$} & $81 \%$ \\
\hline $\begin{array}{c}\text { Jumlah } \\
\text { keseluruhan }\end{array}$ & 195 & - & - & 685 \\
\hline Persentase & - & - & $\begin{array}{c}\text { Sangat } \\
\text { Baik }\end{array}$ & $87,82 \%$ \\
\hline
\end{tabular}


Berdasarkan hasil isian angket yang diperoleh selama ujicoba kelompok besar dapat diketahui persentase penilaian untuk masing-masing aspek indikator yaitu, untuk indikator tampilan media 86\%, indikator kemudahan media $91,6 \%$, indikator kebermanfaatan media $87,5 \%$, dan indikator kesesuaian media $81 \%$. Persentase skor yang didapatkan untuk semua aspek indikator penilaian berada pada rentang per- sentase 75\%-100\%, maka dapat dinyatakan media pembelajaran Pteridisc yang dikembangkan sudah dalam taraf sangat baik untuk digunakan sebagai media penun- jang dalam pembelajaran taksonomi tumbuhan untuk materi Pteridophyta. Dalam ujicoba kelompok besar, selain skor penilaian angket, pengembang juga menda- patkan saran perbaikan mengenai tampilan media. Subjek ujicoba menyarankan untuk lapisan pada media pembelajaran Pteridisc sebaiknya dibuat menggunakan bahan yang lebih keras dan tahan lama. Selain itu, untuk ukuran tulisan subyek ujicoba juga menyarankan agar lebih diperbesar lagi dari ukuran sebelumnya.

\section{PENUTUP}

\section{Kajian produk yang telah direvisi}

1. Pengembangan media pembelajaran Pteridisc taksonomi tumbuhan telah dilaksanakan melalui beberapa taha pan, sesuai dengan model ADDIE.

2. Media pembelajaran yang dikembangkan didesain berbentuk tujuh lapis lingkaran dengan ukuran berbeda-beda tiap lingkarannya. Media yang dikembangkan teridiri atas 20 familia, yang meliputi 16 familia dari class Polypodipsida, 1 familia Marattiop- sida, 1 familia Equisetopsida, dan 2 familia class Psilotopsida.

3. Rerata persentase validasi desain media dan validasi materi yang dapatkan yaitu $75 \%$ dan $86,7 \%$ dengan interpretasi skor untuk tiap item indikator berada pada kategori baik dan sangat baik. berdasarkan hasil yang diperoleh dapat dinyatakan bahwa media sudah layak diujicobakan pada kelompok kecil.

4. Rerata persentase skor yang didapatkan setelah dilakukan ujicoba kelompok kecil dan kelompok besar $94,23 \%$ dan $87,82 \%$ ,dimana interpretasi skor yang didapat untuk masing-masing item penilaian berada pada kategori baik dan sangat baik. Berdasarkan hasil yang diperoleh maka dapat dinyatakan bahwa tangga- 
pan mehasiswa terhadap media yang dikembangkan berada taraf sangat baik.

\section{Saran Pemanfaatan}

1. Penelitian ini dapat dijadikan sebagai masukan dan acuan dalam mengembangkan produk media yang relevan

2. Media pembelajaran ini dapat pula dikembangkan lebih lanjut untuk materi biologi selain taksonomi tumbuhan, ataupun materi untuk mata kuliah lainnya.

3. Penelitian media pembelajaran Pteri disc ini telah mencapai tahap ujicoba kelompok besar dengan jumlah sampel minimum, disarankan bagi peneliti selanjutnya untuk melakukan penelitian dengan jumlah sampel lebih banyak sehingga hasil yang didapatkan mendekati kondisi sesungguhnya.

\section{DAFTAR RUJUKAN}

Ananda, R., B. Hariyadi., Muswita. 2014. ANGDISK: Media Pembelajaran Taksonomi Tumbuhan. Jurnal Pendidi- kan Biologi., 5 (2) : 1222. http://jou rnal.um.ac.id/index.php/jpb/article/ vie $w / 3912 / 0.14 / 9 / 2014$.

Anonim, 2011. Product Magic Disc. http://mediagrafika.com/produkmagic-disc. 19/04/14.

Harmini, 2009. Perbedaan Hasil Belajar Siswa Kelas VIII yang Menggunakan Permainan Bingo dan Magic Disk pada Mata Pelajaran Bahasa Inggris Pokok Bahasan Irregular Verbs di SMP Brawijaya Smart School Malang. Skripsi, Program Studi Tekologi Pendidikan, Fakultas Ilmu Pendidikan Universitas Malang. http://karyailmiah.um.ac.id/index.php/TEP/arti cle/view/5051 18/7/14. 